\title{
La economía del agua en España. Entre lo público y lo privado, la difícil búsqueda del interés general
}

\section{Alberto Garrido Colmenero}

Arbor CLXIV, 646 (Octubre 1999), 217-239 pp.

Toda política económica debe ser enjuiciada con arreglo a su eficacia en la defensa y promoción del interés general. Para enjuiciar la economía política del agua en España, se propone una definición de interés general que integra la provisión de bienes públicos, la promoción de actividades económicas sin efectos externos negativos sobre otros usuarios o sobre el medio ambiente y la reducción de los riesgos asociados con los recursos hidricos. Este trabajo analiza siete postulados de fuerte arraigo en la literatura española en el campo de la política y la economía del agua y enjuicia su compatibilidad con la defensa del interés general. La conclusión central a la que se llega es que tales postulados se muestran relativamente incompatibles con el objetivo de promover el interés general.

Tanto se ha escrito sobre el agua en España en los últimos años que resulta casi arrogante ensayar nuevas ideas e intentar plasmarlas en un artículo. El propósito de este trabajo es examinar ciertos postulados legales, políticos y económicos, que han gozado de gran aceptación en el reciente debate en materia de aguas, y enjuiciarlos desde dos ópticas distintas. A través de la primera se pretende dictaminar si estos postulados constituyen fundamentos válidos para perseguir el interés general, en cuyo concepto englobamos la provisión de bienes públicos, el estímulo de actividades económicas sin efectos externos negativos y la reducción de los riesgos para la sociedad ligados a los 


\section{Alberto Garrido Colmenero}

recursos hídricos y al dominio público hidráulico. A través de la segunda se persigue enjuiciar si favorecen que los incentivos y estímulos al sector privado operan en concordancia con la defensa del interés general. Los riesgos que se asumen con tal propósito son por un lado identificar erróneamente los postulados más relevantes, es decir los que condicionan las actuaciones administrativas, legales y económicas del día a día, y también de los proyectos en discusión, y por otro definir insatisfactoriamente lo que se entiende por interés general. El desarrollo del trabajo exige, por tanto, definir los postulados que se van examinar y adoptar una posición concreta sobre el concepto de interés general. A ambos se dedicará todo el primer epígrafe, tratando de desbrozar el camino que nos permita formular las hipótesis centrales del trabajo, examinar su validez y reflexionar sobre sus consecuencias. El artículo prosigue con el segundo epígrafe abordando el examen relativo a la defensa y promoción del interés general. En el tercer epígrafe, se realiza un ejercicio análogo examinando los efectos de los incentivos y estímulos presentes que actúan sobre las decisiones privadas en materia de uso y gestión del agua. El cuarto y último epígrafe contiene las conclusiones del trabajo y apunta alguna sugerencia que pueda contribuir a superar el bloqueo político en materia de aguas del que ya disertaron Pérez Díaz et al. (1996) en su referenciado libro.

\section{Postulados y definición de interés general}

\section{Postulados (P1-P7)}

P1. La Escasez del agua implica que el agua deba escasear ocasionalmente

Dada la renta del país, la tecnología disponible, el equipo de capital instalado y la oferta natural de la que disponemos, no hay justificación para afirmar que el agua en España deba escasear. Exceptuando algunas situaciones insulares y contadísimas excepciones en la península, jamás debería haber en España problemas de agua que perjudicaran la salud pública, incomodaran a los ciudadanos, provocaran escasez de alimentos 0 se produjeran situaciones de riesgos ambientales importantes. El agua falta en ocasiones porque la demanda para usos no esenciales es excesiva frente a la cantidad de la que se dispone. La oferta natural de agua responde a procesos aleatorios, la demanda es otra variable 
aleatoria correlacionada negativamente con la oferta y, resultando de la combinación de ambas, surge la variable balance hídrico. Del análisis de las variables que afectan al balance hídrico y su naturaleza intrínseca surge el continuo de opciones estratégicas disponibles para intentar conseguir que la probabilidad para la que el balance es positivo sea lo más alta posible. Sin embargo, en ausencia de mercados ágiles, transparentes y competitivos, es posible que se produzcan situaciones de escasez, o de insatisfacción de ciertas demandas. Téngase en cuenta que la acepción que hacemos aquí de demandas no es la del economista sino la del planificador; es decir, hacen referencia a las peticiones de caudales en tiempo, cantidad y calidad que hacen sujetos que detentan derechos concedidos por la administración, mediante los cuales adquieren la naturaleza de demandantes de agua.

Cabe hacer tres apreciaciones sobre la aparición de episodios en los que falta el agua. Primero, en ausencia de algún mecanismo que permita elevar el precio al que ha de pagarse el agua que se usa y que se percibe por ofertarla, es necesario contar con otro que racione su acceso entre los usuarios con derecho a ella. Si no existe tal mecanismo, prevalecerá la regla de la captura y los usuarios aguas abajo no podrán ejercer sus derechos de uso (situación que se dio en el Guadalquivir en 1995, cuando hubo restricciones de uso en Sevilla y meses antes se habían otorgado $120 \mathrm{hm}^{3}$ a los arroceros de las marismas del Guadalquivir). El gran reto institucional es encontrar un equilibrio a mitad de camino entre un pseudo-mercado y la asignación rígida, centralizada y carente de criterios de reparto del agua que gocen de legitimidad. Segundo, la probabilidad de incurrir en un balance hídrico negativo aumenta cuando las demandas que se habilitan concediendo autorizaciones de uso se incrementan a un ritmo superior al que se puede aumentar la media de la oferta natural disponible (en el Guadalquivir, la probabilidad de que algún usuario legal, con concesiones en orden, sufra restricciones es superior al $50 \%$; pero eso no es porque en el Guadalquivir el agua sea escasa, ya que lo es mucho menos que en Canarias o en las Cuencas Internas de Cataluña). Y tercero, el sistema de reparto debe permitir que la probabilidad de que existan demandas insatisfechas sea creciente a medida que los usos son menos esenciales; entendiendo por esencial todo uso del que dependa la salud pública, el bienestar de las personas y la defensa de la vida natural. Con este tercer punto, estamos afirmando que, salvados los usos esenciales para los que la lógica económica no debe ser el criterio prevalente de decisión, el sistema de asignación de agua debe facilitar que el valor económico sea máximo. 
El corolario de este razonamiento es que la escasez de agua genera situaciones de penuria antrópica, ante la que no es justo culpar a la naturaleza sino a las reglas de usos y de utilización que nos hemos dado libremente. La artificial escasez de agua está provocada por la presencia de demasiados demandantes, que son detentadores de derechos de uso, frente a la cantidad de agua que el sistema hidráulico es capaz de proveer ${ }^{1}$.

\section{P2. La tradición histórica de España en materia de aguas es todavía válida y rica en soluciones.}

Muy al contrario, casi nada de nuestra tradición jurídica, política o económica nos sirve ya por dos razones fundamentales. La primera es que esa tradición histórica se explica por el deseo atávico de expansionar, favorecer y potenciar los usos de las aguas; y ahora los tres verbos esenciales son racionalizar, reutilizar y recuperar la calidad de las aguas, objetivos que se presentan en grave contradicción con los que inspiraron la secular quimera del agua. En segundo lugar, porque donde históricamente han prevalecido criterios de racionalidad y se han desarrollado ingeniosas, complicadas y legítimas formas de reparto de aguas, se desdeñaron las consecuencias ambientales del régimen de usos que consagró y nos encontramos con situaciones como las vegas bajas de Júcar y del Segura, que ya no pueden llamarse cursos fluviales. Reparto, gestión de demanda, reducción de riesgos de sequía y recuperación de calidad de aguas y ecosistemas son objetivos inabordables a partir de nuestra tradición histórica. Por si fuera poco, nuestra tradición histórica se plasma en un derecho de aguas que articula hasta lo más minucioso el régimen de utilización de aguas superficiales, especialmente las que han sido alumbradas mediante obras hidráulicas, pero se ha mostrado inadecuado para afrontar los problemas derivados de la sobre-explotación y la contaminación de acuíferos y de los usos conjuntos aguas de superficiales y subterráneas. No podemos depender de nuestra tradición histórica, a pesar de que Moreu Ballonga (1999) y otros la defiendan esgrimiendo criterios jurídicos que en nada favorecen la economía del agua, entendida como un complejo sistema en el que figuran la protección de bienes públicos, la regulación de las acciones privadas y públicas y la reducción de efectos externos. En suma, la tradición histórica no nos ha legado mecanismos para trasladar a los usuarios del agua señales inequívocas del valor social que tiene el agua para una sociedad que acepta la 
existencia de bienes públicos y reconoce la necesidad de proveerlos en una medida razonable y de reducir los efectos externos de la actividad productiva.

\section{P3. Asimilación del concepto de dominio público al de bien público}

Un bien económico de naturaleza pública es un bien de cuyo disfrute no se puede excluir a nadie y cuyo uso o disfrute por parte de un individuo no perjudica ni imposibilita el uso o disfrute de otro. Bajo esta definición, pocos usos normales del agua serían catalogables como bienes públicos; por ejemplo, no lo serían el agua de riego, los usos hidroeléctricos o el abastecimiento de agua. Sin embargo, sí los son precisamente aquéllos que nuestra tradición histórica nunca tuvo sensibilidad en promover: los servicios que presta la calidad del agua, la pesca fluvial, los caudales ecológicos y el paisaje o los usos recreativos. El dominio público de las aguas implica que es el poder público el responsable de que usos públicos y privados no se perjudiquen entre sí, ni deterioren el ámbito territorial o hidráulico en el que fluyen o se almacenan las aguas. Tal y como está definido, el dominio público integra características del agua que son bienes públicos y otras que se corresponden con bienes económicos normales, para los que sí hay exclusividad y rivalidad.

La confusión entre ambos conceptos se traslada generalmente al campo de la financiación de los bienes múltiples que sustenta el recurso agua. Los bienes públicos, por su propia naturaleza, deben financiarse con cargo a impuestos, mientras que los bienes económicos normales pueden financiarse mediante las contribuciones de sus usuarios. El agua empleada para el riego de un parque público no debe concebirse como un bien público y, en consecuencia, es un error esgrimir que al tratarse de un bien público no debe exigirse un pago inspirado en su coste íntegro de provisión. No es un bien público porque el agua empleada se usa en régimen de exclusividad para ese fin y su consumo se debe restar del de otros fines. Lo cual no equivale a afirmar que los visitantes del parque deban pagar por acceder a él, será más bien el titular del mismo quien deba pagar por el agua empleada. Ahora bien el encauzamiento de un río que evita inundaciones sí genera un bien público, porque el que no las haya beneficia a todos en conjunto y no se puede excluir a nadie de su disfrute. Además si no lo hace el poder público, que tiene capacidad coercitiva para recaudar, nunca se hará esa obra y ello a pesar de que para cada individuo fuese 
más rentable pagar un impuesto que tuviera como finalidad llevarla a cabo.

Otro origen frecuente de confusión es asumir que el agua de riego es un bien público y que, en consecuencia, no es lícito que el Estado establezca ninguna tasa de uso que no se corresponda con los costes económicos o financieros originados en servirla. El error es aquí de doble naturaleza: en primer lugar por lo dicho, ningún uso del agua privativo puede ser un bien público; $y$, en segundo lugar, porque siempre que el agua toma el cariz de un bien económico, y eso ocurre cuando no se pueden satisfacer todas sus demandas, tiene un coste de oportunidad que equivale a lo que otro demandante distinto al que la usa estaría dispuesto a pagar por disponer de ella. Que sea muy difícil conceptual y administrativamente establecer una tasa que integre el coste de oportunidad no equivale a afirmar que no tenga coste de oportunidad, en cuyo caso nunca podría ser un bien público ya que sobre él sí habría rivalidad de usos. La actividad económica ligada al agua que genera flujos de renta en nada se asemeja a lo que se entiende como bien público; por tanto, afirmar lo contrario para sustentar que sus usuarios no deban pagar por su uso es un craso error.

P4. Una única administración debe asumir todas las competencias relativas a la gestión del agua

Reconociendo sus servicios a la sociedad, la administración hidráulica ha fracasado en dos tareas esenciales para el futuro de la gestión del agua en España, a pesar de que para su realización disponía de total amparo en la legislación. Nos referimos a la recaudación de cánones y tarifas, y a la defensa y protección de los bienes públicos que la legislación contempla como integrantes del dominio público hidráulico. De lo primero deriva, por ejemplo, que las demandas de agua para nuevos regadíos resulten injustificables si se enfrentan al coste de inversión que exigen (cuestión que han demostrado Sumpsi Viñas et al. 1998). Reconociendo su propia incapacidad, la administración ha creado empresas públicas aportando la mitad de su capital social para que éstas se encarguen de cobrar las tasas a los usuarios de las obras que ejecuten. De lo segundo deriva la actual situación de deterioro ambiental de muchos de nuestros ríos y embalses. Cabe aquí preguntarse por qué no se otorga a organismos independientes la gestión de ciertas responsabilidades, contra cuyo incumplimiento o negligencia los ciudadanos pueden ir con mejores posibilidades de éxito judicial que si 
lo hacen contra una administración cuando no recauda lo que la ley dice que debe recaudar o deja que se deteriore la calidad de las aguas $\mathrm{y}$ los ecosistemas fluviales. El régimen administrativo de las aguas en España coloca dos ámbitos de responsabilidad sobre una misma rama del ejecutivo, cuáles son, la gestión del régimen económico-financiero -que incluye diseño de tarifas, cánones y cobro de los mismosy la provisión y defensa de los bienes públicos, que incluye, entre otras, labores de policía y vigilancia del dominio público hidráulico e incoación de expedientes sancionadores a los causantes de vertidos ilegales. Contra la negligencia de la administración al llevar a cabo ambas tareas nada se puede hacer, puesto que es muy difícil demostrar ante otras instancias que cobra mal por los servicios que debería cobrar diligentemente o que actúa negligentemente en llevar a cabo los servicios de defensa del dominio público que tiene asignados. Las consideraciones jurídicas que haya que hacer en cada caso sobrepasan el objetivo del trabajo y la especialidad de su autor; ahora bien, tienen dos consecuencias en el plano económico que merece la pena remarcar. Primero, el notable desfase entre tarifas y cánones y los costes que supuestamente pretenden cubrir, junto al hecho de que muchos usuarios escapen de sus obligaciones impositivas, exonera en parte a los organismos de cuenca para llevar a cabo las tareas que tienen asignadas, ya que éstos siempre pueden esgrimir que no cuentan con suficientes recursos financieros. Segundo, como consecuencia de lo anterior, los servicios ligados al dominio público que más sufren las consecuencias de actuar con penuria económica son los que tienen naturaleza de bien público. Ello es debido a que no existen mecanismos judiciales adecuados para ir contra la administración cuando su negligencia no ocasiona daños o perjuicios a servicios que no están ligados a ninguna concesión o autorización administrativa de usos. En resumen, al existir lenidad en materia de cobros, la propia administración encuentra una excusa para actuar negligentemente en materia de defensa y promoción de bienes públicos, precisamente donde más difícil es atacarla.

P5. Los derechos de uso del agua se definen como concesiones administrativas de naturaleza no reciproca, con imposibilidad de alterar alguna de sus propiedades y que, mediante la facultad reordenadora de la administración, puede conseguir que los titulares hagan un uso racional del agua

Pocos ponen en tela de juicio la naturaleza de las concesiones hidráulicas e incluso defienden su vigencia incluso en un contexto en 
el que puedan llegar a intercambiarse en un mercado. Cuando el poder público autoriza un nuevo uso mediante una concesión sin asumir ninguna obligación sobre la garantía con la que debe servir el caudal concedido, el estímulo a concederlas con excesiva prodigalidad es demasiado fuerte (ver nota final 1). Como además su titular apenas deberá pagar por disfrutarla, el estímulo para exigir de la administración rigor a la hora de examinar nuevas peticiones es nulo. El resultado es que se han habilitado usos, se han creado derechos y favorecido inversiones en torno a ellos, formando una hipotética entente entre usuario y administración hidráulica de negativas consecuencias. Primeramente, porque la aparición de una sequía acaba exigiendo la aportación con cargo a presupuestos generales de ayudas económicas, cuando tal vez esa concesión nunca se habría debido tramitar, ya que en parte el aumento de la probabilidad de que se entre un período de sequía hidrológica es consecuencia de la aprobación de esas concesiones. Segundo, porque tal entente opera en virtud de un equilibrio de bajo nivel institucional, según el cual la administración concede lo que se le pide y cobra al concesionario poco o nada, y éste a su vez acepta las condiciones y no exige responsabilidad alguna a aquélla por sus incumplimientos o negligencias; siendo el caso también que las consecuencias financieras de las medidas de alivio por sequías nunca recaen en los presupuestos de la administración hidráulica, una de cuyas obligaciones es reducir los riesgos de que aparezcan sequías hidrológicas.

La segunda parte del postulado se refiere a la práctica imposibilidad de alterar alguno de los elementos que definen una concesión. Con ello, se anclan los usos a tecnologías caducas, se favorecen cultivos cuya rentabilidad social se desvaneció hace lustros y se consolidan patrones de usos en franca discordancia con las necesidades actuales y futuras del país. El Proyecto de Modificación de la Ley de Aguas, a fecha de hoy en fase de discusión parlamentaria, contempla la posibilidad de establecer intercambios de concesiones sin que se altere la naturaleza de las mismas, respetando los principios con que se definieron en la Ley de Aguas (1985). Cabe dudar sobre las posibilidades de éxito de un mercado en el que lo que se va a intercambiar tiene una incierta y arbitraria naturaleza; incierta, porque el agua a que da derecho varía cada año y no sólo en función de lo que llueva, sino más bien estando en mayor medida en función de lo que los órganos de los organismos de cuenca decidan, no siendo baladí recordar que en tales órganos están representados los propios titulares de las concesiones, que también serán participantes en el mercado. Dijimos también arbitraria, porque las concesiones en España tienen un orden 


\section{La economía del agua en España}

de prelación de usos en función del destino del agua concedida; de esta forma, los abastecimientos tienen prioridad sobre los riegos, y éstos sobre los usos industriales, etc. De aprobarse tal y como se envió al Parlamento, lo único que se podrá cambiar en una concesión a través de los intercambios es el titular y el tipo de uso, pero sólo se autorizará el intercambio cuando el comprador sea un titular de igual o mayor prelación que el vendedor. Retomemos el postulado: las concesiones administrativas, o derechos de uso en definitiva, podrán ser objeto de intercambio en un mercado sin perder su naturaleza de concesión administrativa, que hemos calificado de no reciprocidad, nacida de la excesiva prodigalidad y que da derecho a algo arbitrariamente definido en órganos en los que están los propios participantes del mercado. Cabe dudar de la eficacia de una simbiosis tan delicada como mercado y derechos intercambiables, tal y como están y estarán definidos ambos.

Finalmente, se señala la facultad reordenadora de las concesiones que tiene la administración para promover el uso racional y cauteloso del agua. Con ello la administración podría cancelar concesiones para habilitar nuevos usos más esenciales, pero la experiencia demuestra que intervenciones de este tipo son muy infrecuentes y no cabe esperar que vayan a prodigarse en el futuro. En las grandes cuencas españolas muchos regantes dependen de las obras de regulación general (embalses, fundamentalmente), que cuentan con una reserva al inicio de cada campaña de riegos con la que se calculan las dotaciones para sus riegos. Una comunidad de regantes que estimara que la dotación de riego asignada fuera excesiva, incurriendo en un riesgo elevado de que al año siguiente no quedaran recursos para el riego, no tiene estímulo alguno para solicitar que se le reserve para el año siguiente una parte de su dotación. Esto es debido a que el volumen ahorrado entraría a formar parte del pool de recursos disponibles para toda la cuenca, con lo que a la comunidad ahorradora no le llegaría más que una fracción mínima del volumen ahorrado. Tal y como están definidas las concesiones, el incentivo al ahorro es escaso porque la titularidad de las aguas al inicio de una campaña corresponde al conjunto de todos los usuarios que se sirven de ellas. Ahora bien, que un titular individual no esté estimulado al ahorro no impediría que el conjunto de los usuarios sí lo estuviera. Cabe entonces plantearse la posibilidad de que el colectivo pudiera actuar cautelosamente, demandando dotaciones bajas en los años en que el volumen embalsado no sea muy elevado en previsión de que una sequía meteorológica se convierta en sequía hidrológica al período siguiente. Tal hipótesis no se ha mostrado 
como cierta y todavía se trabaja en dilucidar las razones que expliquen una conducta tan miope o arriesgada, según se mire (Garrido y Gómez-Ramos, 1999) ${ }^{2}$.

P6. La gestión de la demanda perjudica al conjunto de demandantes que son "gestionados"

Para refutar este segundo postulado, tan arraigado entre nuestros usuarios agrícolas, es necesario definir qué entendemos por gestión de demanda. Con cierta laxitud, se ha asociado gestión de demanda a todo sistema de asignación de agua no basado en la expansión de la oferta, lo que equivale a hablar de cualquier criterio mediante el cual se repartan los recursos disponibles. Eso implica hacer uso de algún sistema de tasas o precios, repartir cuotas entre usuarios o implantar algún mecanismo de mercado. Con frecuencia se arguye que los sistemas de gestión de demanda no se implantan porque siempre se puede encontrar un conjunto de usuarios que se vea perjudicado y bloquee eficazmente su aplicación. Sin embargo, los sistemas de gestión de demanda pueden conseguir explotar tres hechos que suelen ignorarse. Primero, que los sistemas de gestión de demanda buscan gravar el consumo de agua y no recaudar indiscriminadamente sobre todos los usuarios con independencia de su consumo; con lo cual son mucho más justos. Segundo, que cualquier sistema de reparto de aguas que esté acompañado de un mecanismo que le dote de autonomía financiera, es decir que esté enteramente financiado por sus propios usuarios, funciona con mayor fiabilidad y agilidad, y contará con un equipo de capital más adaptado al régimen de oferta natural que explote; será, por tanto, menos vulnerable a las situaciones de sequía hidrológica, beneficiando a todos los usuarios que lo integren. Puede parecer tautológico, pero un mecanismo de gestión de demanda plantea un protocolo de actuaciones que previene situaciones para las que la gestión de demanda se mostraría necesaria; de ahí que afirmemos que un sistema bien autofinanciado será menos proclive a la necesidad de tener que racionar el agua. Tercero, existe la posibilidad de fragmentar las demandas por bloques de consumo, estación o período de tiempo, otorgando a cada unidad de consumo un tratamiento diferenciado en materia de precio y posibilidad de intercambiarse en mercados más o menos restringidos. Con ello se conseguiría separar usos esenciales de los que no son, gravando estos últimos a la disposición al pago de sus usuarios y reservando a los esenciales un acceso a precios inspirados 
estrictamente en costes variables o subvencionados por los primeros. Las posibilidades de extraer ganancias a través del mercado que contribuyan a financiar usos generales, servicios básicos o incluso bienes de naturaleza pública para el conjunto de usuarios ya ha sido concebido en algunos lugares (Easter, Rosegrant y Dinar, 1998; Parker y Tsur, 1998). Las resistencias a cambiar a un sistema de gestión de demanda se originan por la incertidumbre implícita en definir el nuevo status quo, a partir del cual entran en funcionamiento las nuevas reglas que fundamentan un sistema de gestión de demanda eficiente, justo, legítimo, seguro, de resultados previsibles y suficientemente flexible (Howe et al. 1986).

P7. El régimen económico y financiero del sistema de abastecimiento de agua debe proteger a los usuarios de bajo nivel de ingresos y a los usuarios cuya actividad productiva no permite sufragar los costes íntegros del agua

En economía está bien probado que un único instrumento económico no debe emplearse para varios fines, sobre todo cuando éstos son tan dispares como asegurar una vida materialmente digna a los ciudadanos más humildes y financiar un sistema de oferta de agua que estimule un uso racional. La realidad nos dice que el sistema tributario del Estado y la política asistencial tienen mayores posibilidades de complementar la renta de los más desfavorecidos que la empresa que abastece de agua a una ciudad. De igual modo, la mejor vía para facilitar alternativas a unos regantes que no pueden financiar los costes íntegros del agua que emplean no es seguir subvencionando el uso del agua, porque la sociedad gana más si otros la emplean o los recursos se destinan a favorecer otras actividades económicas que no imputen costes elevados a la sociedad. Cuando la sociedad da muestras de valorar que haya actividad agrícola operativa en zonas con riesgos de despoblamiento, hay mecanismos para otorgar ayudas financieras a los agricultores que mantengan su actividad productiva sin que por ello deban usar recursos que la sociedad valora más destinándolos a otros usos. Cuando se dice que ciertas actividades generan empleo, renta o actividad económica positiva, y que por ello deben protegerse, tal aseveración debe pasar un doble tamiz para comprobar primero si se valoran los recursos naturales a su coste de oportunidad; y segundo si se valora la actividad económica generada por el valor social que genera, es decir, valorando los bienes y servicios generados a sus precios 
de mercado, descontando los daños ambientales generados o a los precios percibidos por los productores, incluyendo las subvenciones explícitas 0 implícitas.

Al examinar este postulado no se puede omitir una valoración sobre el recurso judicial ganado por las familias barcelonesas a la antigua Junta de Aguas de la administración catalana, en cuya sentencia se obliga a que la factura del agua de un hogar tenga presente, entre otras cosas, si se trata o no de una familia numerosa (Saurí y Muñoz, 1999). Desde una óptica de justicia económica, tal sentencia probablemente no ofrece grandes garantías de que el precio reducido a las familias numerosas ayude realmente a las personas que necesitan asistencia económica para sufragar un bien básico como el agua. Primero, porque hay familias numerosas de renta alta, segundo porque hay familias no numerosas de renta baja y tercero porque tal medida exige un control administrativo para verificar con periodicidad el tamaño o la renta del hogar, que probablemente no está al alcance de la empresa que sirve las aguas. Además, también habría que hacerlo para el gas, la electricidad, el vestido, y ipor qué no los bienes de alimentación y aseo infantil? Precisamente, para dotar de asistencia económica al desfavorecido está el sistema tributario que tiene una capacidad técnica de control mucho mayor y que tiene en cuenta muchos más aspectos que el tamaño de la familia.

\section{Una definición del interés general}

Definimos el interés general, optando deliberadamente por la parquedad, como todo aquello que facilita la provisión de bienes públicos, favorece la generación de riqueza desarrollando actividad económica productiva sin efectos externos negativos y reduce los riesgos para la salud, para la vida y para el bienestar de las personas. Ante la acusación de que se trata de una definición peligrosamente reduccionista, se puede responder que sólo hablamos de gestión de un recurso natural o también que no deberíamos pensar en objetivos más sofisticados si por el momento los más básicos son usualmente desdeñados. Por otro lado, desviaciones significativas de este triple objetivo tienen unos costes probados, como se viene argumentando aquí. Recordemos que España está todavía en una fase en la que no sólo no se penalizan las actividades ' con efectos externos, sino que se promueven con políticas públicas; se desdeñan los servicios ambientales promocionando proyectos de rentabilidad financiera dudosa que los deterioran; y se asumen conside- 
rables riesgos de sequías e inundaciones, sin que de tales eventos se deriven responsabilidades públicas . El interés general se promueve, por ejemplo, favoreciendo la actividad agrícola del regadío que genera productos de alta valoración en el mercado con impactos ambientales reducidos o mínimos, reduciendo la probabilidad de aparición y la intensidad de las sequías hidrológicas, imputando a los usuarios del agua el coste completo de la oferta, incluyendo el de depuración y tratamiento, incrementando la competencia y la capacidad reguladora de los organismos de defensa de la competencia en el sector de abastecimiento del agua y poniendo en pie de igualdad la defensa de los usos ambientales.

\section{La defensa del interés general}

Convengamos en aceptar que los poderes públicos deben promover el interés general y que éste quedaría definido por sus tres componentes: bienes públicos, actividad económica sin efectos externos y reducción de riesgos. El Cuadro 1 trata de resumir las correspondencias entre objetivos del interés general y los postulados que hemos definido anteriormente.

\section{La reducción de riesgos}

En unos tiempos en los que el papel del sector público en numerosas áreas de nuestra economía está siendo tan cuestionado, ha arraigado con fuerza la creencia de que el Estado sí debe actuar con el objetivo de reducir los riesgos que amenazan el bienestar social o el clima que propicia el crecimiento sostenido de la actividad económica. El tradicional postulado de la escuela de economía de la Universidad de Chicago, según el cual los riesgos siempre pueden cubrirse favoreciendo el mercado de seguros, ha perdido muchos adeptos. Sequías, terremotos, incendios, inseguridad alimentaria, riesgos de contagios, aludes, inundaciones, olas de calor, huracanes, accidentes en grandes industrias, seguridad en el transporte son riesgos para cuya reducción es necesaria la intervención del sector público. Nuestra política hidráulica ha conseguido éxitos notables en la reducción de riesgos por inundación, si bien los organismos responsables de la ordenación de uso del suelo han provocado que se produjeran graves episodios, motivados por la ocupación ilegal de suelo perteneciente a la superficie inundable $y$, por tanto, al dominio público. 
CUADRO 1. Examen resumido de axiomas y postulados sobre su contribución a la defensa del interés general

\begin{tabular}{|c|c|c|c|c|}
\hline \multirow[b]{2}{*}{ POSTULADOS } & \multicolumn{4}{|c|}{$\begin{array}{l}\text { COMPONENTES DEL INTERÉS GENERAL } \\
\text { ¿contribuyen los postulados a la... }\end{array}$} \\
\hline & $\begin{array}{l}\text {...provisión de } \\
\text { bienes públicos? }\end{array}$ & $\begin{array}{l}\text {..reducción de } \\
\text { efectos externos } \\
\text { negativos? }\end{array}$ & $\begin{array}{l}\text {...reducción de } \\
\text { riesgos? }\end{array}$ & $\begin{array}{l}\text { Balance } \\
\text { general }\end{array}$ \\
\hline $\begin{array}{l}\text { P1. Noción de } \\
\text { escasez de } \\
\text { agua }\end{array}$ & $\begin{array}{l}\text { No. Los bienes } \\
\text { públicos no son } \\
\text { demandas que se } \\
\text { incorporen a la usual } \\
\text { noción de escasez }\end{array}$ & $\begin{array}{l}\text { No. La presión sobre } \\
\text { los recursos agrava } \\
\text { los efectos externos. } \\
\text { Dar por válidas } \\
\text { demandas que } \\
\text { contaminan. }\end{array}$ & $\begin{array}{l}\text { No. La noción de } \\
\text { escasez no integra } \\
\text { mediciones de } \\
\text { riesgos, ni los } \\
\text { considera }\end{array}$ & Muy negativo \\
\hline $\begin{array}{l}\text { P2. Validez de la } \\
\text { tradición } \\
\text { histórica }\end{array}$ & $\begin{array}{l}\text { No. No se concebia su } \\
\text { existencia, mucho } \\
\text { menos la necesidad } \\
\text { de defenderlos }\end{array}$ & $\begin{array}{l}\text { No. Promueve la } \\
\text { expansión de los } \\
\text { usos, de manera } \\
\text { general, incluidos los } \\
\text { que generan efectos } \\
\text { negativos }\end{array}$ & $\begin{array}{l}\text { No. La gestión que se } \\
\text { deriva de la tradición } \\
\text { no internaliza el } \\
\text { objetivo de reducirlos }\end{array}$ & Negativo \\
\hline $\begin{array}{l}\text { P3. Dominio público } \\
\approx \text { Bien público }\end{array}$ & $\begin{array}{l}\text { No. Sustenta la idea } \\
\text { de que los usuarios } \\
\text { del dominio público } \\
\text { deben ser } \\
\text { subsidiados }\end{array}$ & $\begin{array}{l}\text { No. Al subsidiarse } \\
\text { usos que generan } \\
\text { efectos externos }\end{array}$ & $\begin{array}{l}\text { No. La reducción } \\
\text { de riesgos es, en } \\
\text { general, un bien } \\
\text { público que se } \\
\text { desestima }\end{array}$ & Negativo \\
\hline $\begin{array}{l}\text { P4. Una única } \\
\text { administración }\end{array}$ & $\begin{array}{l}\text { No. La provisión de } \\
\text { usos privativos y } \\
\text { bienes públicos recae } \\
\text { sobre la misma } \\
\text { admón. }\end{array}$ & $\begin{array}{l}\text { No. No da cuentas } \\
\text { ante nadie del estado } \\
\text { de la calidad de las } \\
\text { aguas ni de la } \\
\text { consecución de logros }\end{array}$ & $\begin{array}{l}\text { No, los riesgos no son } \\
\text { asumidos por la } \\
\text { administración cuyas } \\
\text { decisiones los causan }\end{array}$ & Negativo \\
\hline $\begin{array}{l}\text { P5. Definicion } \\
\text { correcta de } \\
\text { derechos }\end{array}$ & Neutro & $\begin{array}{l}\text { No. Protege a lo } \\
\text { titulares causantes } \\
\text { de efectos externos } \\
\text { negativos }\end{array}$ & $\begin{array}{l}\text { No. No hay suficiente } \\
\text { grado flexibilización } \\
\text { para reducir ni } \\
\text { graduar los riesgos } \\
\text { para distintos usos }\end{array}$ & Negativo \\
\hline $\begin{array}{l}\text { P6. Gestión demanda } \\
\text { perjudicial para } \\
\text { "gestionados" }\end{array}$ & $\begin{array}{l}\text { No. Hay ganancias } \\
\text { netas de rentas que } \\
\text { pueden financiar } \\
\text { bienes públicos }\end{array}$ & $\begin{array}{l}\text { No. Los agentes } \\
\text { "gestionados" } \\
\text { reducen sus efectos } \\
\text { externos }\end{array}$ & $\begin{array}{l}\text { No. Los sistemas de } \\
\text { gestión de demanda } \\
\text { reducen la } \\
\text { vulnerabilidad } \\
\text { a riesgos }\end{array}$ & Negativo \\
\hline $\begin{array}{l}\text { P7. Trato económico } \\
\text { favorable a } \\
\text { ciertos usos }\end{array}$ & $\begin{array}{l}\text { No. Estimula el uso } \\
\text { del agua }\end{array}$ & $\begin{array}{l}\text { No. Estimula usos } \\
\text { contaminantes del } \\
\text { agua }\end{array}$ & $\begin{array}{l}\text { No. Incentiva usos } \\
\text { y aumenta la } \\
\text { vulnerabilidad a } \\
\text { riesgos }\end{array}$ & Muy negativo \\
\hline
\end{tabular}

Las sequías continúan siendo un área de escasa atención preventiva y estratégica. Se actúa en materia de auxilio a los afectados tarde, mal y descargando de toda responsabilidad tanto a los responsables de la gestión del agua y como a los usuarios que toman decisiones en los órganos decisores de los organismos de cuenca (ver nota 3). 
El Libro Blanco de las Aguas (MIMAM, 1998) dedica a la sequía seis páginas de las 950 que tiene, lo cual es cuando menos paradójico por varias razones. En primer lugar, porque las sequías más graves que nos aquejan son las hidrológicas, ya que las meteorológicas no se pueden evitar y han inspirado un avanzado sistema de seguros agrarios, que no tiene parangón en otros países europeos. Prevenir las sequías hidrológicas es un objetivo prioritario para el que no se ha diseñado una estrategia adecuada, a pesar de que se trata de un área en el que ya se ha avanzado mucho (Calatrava et al. 1998). Segundo, porque la discrecionalidad de los organismos de cuenca para aplicar estrategias preventivas es casi total, por lo que parecería lógico que se hubiera trabajado en esta dirección con proyectos de evaluación de riesgos de sequía y aplicación de sistemas expertos, tal vez inspirados por modelos de evaluación de riesgos financieros (Watters, 1995). Y tercero, porque nuestro país cuenta con un importante activo en embalses, que deberían ser gestionados con criterios económicos y no sólo hidrológicos (Garrido y Gómez-Ramos, 1999). La reducción de riesgos exige desarrollar modelos aplicables de medición y caracterización. Actualmente, el único índice aplicado en España de sequía hidrológica es el porcentaje de ocupación de los embalses.

\section{La reducción o eliminación de efectos externos negativos}

Una externalidad negativa se produce cuando un agente lleva a cabo a actividades que perjudican a un tercero sin que éste pueda reclamar una compensación ni el causante tenga en cuenta el coste que le imputa a la víctima. Muchos usos del agua generan externalidades negativas: vertidos tóxicos en estuarios, escorrentías contaminadas por el ganado que acaban en embalses de regulación para abastecimientos, etc. El desdén de los bienes públicos y de la contaminación de las aguas ha sido fruto de la consagración de unos derechos de propiedad - property rights, no en el sentido jurídico del término- que han favorecido y protegido la actividad del causante de la externalidad. Para revertir la situación es necesario redefinir esa estructura de derechos de propiedad, lo cual implica convertir a la víctima en titular de un derecho, que le acredita para disfrutar de unas aguas limpias, y al causante en un infractor de la ley. Sin embargo, para que tal inversión del derecho logre el objetivo final de mejorar la calidad de las aguas son necesarias tres condiciones, todavía ausentes en nuestro modelo de gestión de las aguas. Primero, que se definan los objetivos am- 


\section{Alberto Garrido Colmenero}

bientales que se persiguen, en materia de parámetros de calidad de aguas, caudales ecológicos, plazo de tiempo en el que deben cumplirse y sistema de verificación, supervisión y control. Segundo, debe definirse el período de tiempo en el que los causantes de efectos externos deberán adaptar sus sistemas productivos o cesar su actividad contaminadora. $\mathrm{Y}$, tercero, y en un plazo similar al anterior, debe decretarse la eliminación completa de todos los estímulos públicos que favorecen las actividades que generan efectos externos, ayudándose, tal vez, con estímulos a la adopción de tecnologías de producción limpias. Las tres condiciones son necesarias, pero no suficientes; si como Rawls (1973) nos enseña, la normativa empieza a aplicarse con demasiadas excepciones, disposiciones transitorias abusivas o situaciones cautelares, el mensaje que se trasladará a aquellos con voluntad de cumplimiento será que no merece la pena o que es demasiado costoso, al ver que sus rivales $u$ homólogos son fácilmente exonerados del esfuerzo de adaptación y de cumplimiento.

\section{La promoción de los bienes públicos}

Como también nos dice Rawls (1973), toda sociedad constitucionalmente establecida se basa entre otros en dos principios esenciales: el cumplimiento generalizado de las normas y la seguridad generalizada del que incumple es perseguido y sancionado de tal forma que el beneficio de incumplir es inferior a la magnitud de la sanción. El se refería a los sistemas impositivos y de redistribución de riqueza de un país, pero la idea es perfectamente aplicable a la gestión de los bienes públicos. Un bien público tiene la doble cara de que se disfruta sin trabas, exclusividad o rivalidad, pero hay que financiarlo o contribuir a su provisión mediante medidas coercitivas. Por el lado de la financiación, poco hemos avanzado si tomamos en cuenta que ni siquiera los usuarios de carácter privativo contribuyen con sus cánones y tarifas a financiar los costes íntegros que se originan en servir las aguas que emplean para fines de lucro. Por ello, en el estado actual de las cosas del agua no cabe esperar que el interés general pueda ser promovido eficazmente, ya que la administración debe destinar sus presupuestos a cubrir los costes que los usuarios privativos no cubren con sus aportaciones.

Por el lado de la responsabilidad en proveer bienes públicos, también ha de hacerse una valoración crítica. La calidad ambiental de nuestro dominio público hidráulico difícilmente será mejorada si el organismo 


\section{La economía del agua en España}

público encargado de velar por ella forma parte del poder ejecutivo y además tiene la responsabilidad de autorizar su uso y administrarlo. Otros países han creado agencias ambientales independientes que vigilan el uso de los recursos y emprenden acciones contra quiénes perjudican su calidad ambiental, incluidas las administraciones públicas. Los ciudadanos deberían poder otorgar a una agencia independiente del poder ejecutivo la tarea de velar por sus recursos y de informar al público sobre qué entidades, administraciones, empresas o ciudadanos realizan actividades que perjudican la calidad ambiental del dominio público hidráulico.

\section{El gasto del Ministerio de Medio Ambiente en 1999}

Para verificar la correspondencia entre las valoraciones que se hacen y la realidad, parece indicativo examinar las decisiones de gasto del Ministerio de Medio Ambiente en los primeros meses de 1999, en obras licitadas y en obras adjudicadas. La información se resume en el Cuadro 2.

CUADRO 2. Distribución del gasto en inversiones en materia de aguas del Ministerio de Medio Ambiente (primeros meses de 1999)

\begin{tabular}{|l|c|l|c|}
\hline \multicolumn{1}{|c|}{ Licitaciones } & \multicolumn{1}{|c|}{ Porcentaje } & \multicolumn{1}{|c|}{ Adjudicaciones } & Porcentaje \\
\hline $\begin{array}{c}(39.500 \text { millones de } \\
\text { pesetas) }\end{array}$ & (cifras aproximadas) & $\begin{array}{c}(29.400 \text { millones de } \\
\text { pesetas) }\end{array}$ & (cifras aproximadas) \\
\hline Regadíos & $40 \%$ & Usos diversos & $63 \%$ \\
\hline Bienes públicos & $31 \%$ & Bienes públicos & $10 \%$ \\
\hline Depuración & $29 \%$ & Depuración & $27 \%$ \\
\hline
\end{tabular}

Fuente: Cinco Días (27/8/1999) y elaboración propia

Como se ve en el cuadro la provisión de bienes públicos es el capítulo menor, precediéndola en su importancia la depuración y la provisión de usos privativos. Estos datos confirman que la administración suple la insuficiente cuantía cobrada a través de las tarifas para cubrir los costes íntegros de los usuarios, incluidas la depuración de las aguas servidas, y dedica una parte importante de su gasto en inversión a promover los usos del agua, entre los que todavía destaca el regadío. 


\section{Los estímulos y los incentivos privados}

Poco puede hacer el sector público sin que los agentes regulados reciban señales para que la búsqueda legítima de su interés privado no sea a costa del deterioro del interés público. Los estímulos que operan en las decisiones privadas son de muy diversa índole: los hay evidentes y claros, como pueden ser los de una política que promueva la adopción de nuevas tecnologías de riego, y más difusos o borrosos, pero no por ello menos influyentes en las decisiones privadas, como es el criterio que presida la definición de los derechos de propiedad. En ocasiones, los estímulos difusos o borrosos pueden tener una influencia mayor en las decisiones privadas. Por ejemplo, la Ley de Colonización y Grandes Zonas Regables de 1949, todavía vigente, establece unas condiciones de financiación para los futuros regantes muy favorables, y al amparo de ella existen grandes zonas regables en España que disfrutan de un acceso al agua a precios que ni siquiera han permitido sufragar el coste íntegro de las obras de interés privado.

En el caso del agua, la presencia de incentivos perjudiciales para el interés general no es fruto de decisiones erróneas ni siquiera viciadas por intereses particulares, es sencillamente el resultado de aplicar políticas pasadas en las que lo sustantivo era potenciar el uso del agua, facilitar su explotación y extraer los beneficios máximos a los recursos que se iban haciendo disponibles. Por ejemplo, el objetivo de aumentar la producción de forrajes, que permitiese el desarrollo de una ganadería menos dependiente de los pastos naturales tan vulnerables a las sequías meteorológicas y más en consonancia con las rentas y los gustos de las familias españolas de los años sesenta, explica en gran medida al empuje público al regadío en el período 1955-75.

La dificultad con la que nos encontramos actualmente en materia de estímulos e incentivos privados radica en que hay que invertir el signo de muchos de los que están presentes en nuestro modelo de gestión del agua. Lo que antes se promovía con notable esfuerzo financiero público, ahora hay que desestimularlo o al menos potenciar cambios notables en los modelos productivos presentes. En materia de regadíos, hemos defendido que la política de tarifas no sería el mecanismo más adecuado para desestimular el consumo del agua de nuestros regantes, aún cuando sí lo sería para incrementar la contribución de estos para sufragar los costes de los organismos de cuenca y los de sus propias comunidades (Sumpsi et al. 1998). Sin embargo, un examen detallado del complicado entramado de incentivos, efectos secundarios y definiciones imperfectas de los derechos que se pretenden 
regular muestra que redactar normativas dirigidas a potenciar el ahorro del agua en la agricultura constituye una tarea compleja.

Examinemos, si no, el aparentemente simple objetivo de mejorar las conducciones de agua y las técnicas de riego de una comunidad de regantes. Si damos ayudas a una CR para que mejore sus conducciones, aumentando así la fracción del caudal que llega a la planta respecto de la que se desembalsa, probablemente los regantes se beneficiarán, pero para el resto de la sociedad puede suponer un doble coste financiero, por tener que pagar una parte de las obras, e hidrológico, porque esa fracción de caudal que antes se perdía de la CR ya no volverá a los cauces aguas abajo. El resultado probable es que los regantes gasten más agua ahora que antes, cuando eran ineficientes. Opcionalmente, se les puede dar la ayuda sujeta a la condición de que el caudal al que tienen derecho sea reducido, en cuyo caso la mejora puede tener efectos positivos para el conjunto de la cuenca y los regantes regarán en mejores condiciones técnicas. Sin embargo, se demuestra que cuando se revisa su dotación los incentivos que tiene una $\mathrm{CR}$ para acogerse a un programa de mejora de sus instalaciones se reducen notablemente, por lo que el Estado debe pagar un porcentaje elevado de la obra arrojando sombras sobre la rentabilidad económica de ejecutarlo (Garrido et al. 1997; Blanco Fonseca, 1999). Michelsen et al. (1998) demuestran que los intentos del Bureau of Reclamation - un gigantesco instituto público de transformación en regadío en EEUU, a cuyo cargo se han transformado 20 millones de hectáreas - por hacer que sus regantes ahorren agua han dado ambiguos resultados.

Las dificultades inherentes al objetivo de que los agricultores rieguen con menos agua no implican que se deba renunciar al objetivo de revertir un esquema de incentivos que ya no está en concordancia con el interés general. Probablemente es más eficaz perseguir el incentivo buscado mediante la opción de autorizar a los regantes a vender el caudal que no les sea rentable emplear al precio ofrecido por posibles compradores. Recientemente, he disertado sobre el Proyecto de Ley de Modificación de la Ley de aguas, en fase de discusión parlamentaria, algunos de cuyos nuevos preceptos están dirigidos a facilitar la aparición de intercambios voluntarios de agua o, mal llamados, mercados de agua (Garrido, 1999). Señalé entonces que dicho Proyecto contiene demasiadas cautelas donde no serían necesarias, ocasionando retardos y obstáculos a los intercambios futuros, pero que atribuye al poder tutelar del Estado para supervisar los intercambios una eficacia no demostrada hasta la fecha, siendo esta apreciación coincidente con la de Embid Irujo (1999). 
Desplegar sobre nuestra economía del agua un manto nuevo de incentivos que redirija las acciones privadas hacia el interés común es un objetivo que precisa de diferentes elementos. No es sensato, como se ha demostrado en Australia, implantar un mercado de aguas, si no se obliga a todos los titulares de los derechos intercambiables en el mismo a que paguen una proporción parecida de los costes del suministro y se eliminan los subsidios cruzados que tanto lo distorsionan. Inversamente, un sistema basado exclusivamente en las tarifas públicas no surtirá efectos si no se acompaña de un mecanismo positivo de respuesta, permitiéndose al usuario que no sólo se ahorre el pago del agua no consumida sino que la ceda a cambio de una compensación económica. Finalmente, ambas cosas, tarifas recuperadoras de costes y posibilidades de intercambio, caerían en saco roto si no se agregan otras dos acciones, como son: la redefinición de las concesiones a las que tiene derecho cada usuario, es decir, decidir qué es justo que posea cada uno en vista de lo que hace, de otras demandas alternativas, de la técnica disponible y de los recursos con los que cuenta; y, en segundo lugar, la erradicación completa del apoyo del sector público a proyectos que generen nuevas demandas para fines productivos sin que sus beneficiarios finales puedan pagar el coste íntegro de llevarlos a cabo; especialmente de aquéllos que proyectos que generan efectos externos negativos.

\section{Reflexiones finales}

El prolijo debate del agua en España no ha dado pié todavía al examen riguroso de las distintas opciones políticas y programáticas disponibles, algunas de las cuales han sido probadas por otros países. Es fácil sucumbir a la tentación de interpretar el retraso de la puesta en práctica de nuevas políticas del agua como un caso típico de atenazamiento político por parte de los regantes y otros sectores, logrando impedir que se lleven a cabo las reformas que de una forma u otro todos los analistas coinciden en demandar. Si esa interpretación fuera válida, las reformas australiana, francesa o californiana tampoco se habrían llevado cabo. La atención continuada hacia lo que dicen, hacen y escriben los responsables de la gestión del agua de diverso signo político parece más bien sustentar la tesis de que no están convencidos de la necesidad de llevar a cabo las reformas que persigan algunas de las ideas esbozadas aquí. A veces, pareciera que no entienden de lo que hablan o que no entienden el razonamiento lógico que sustenta 
muchas de las propuestas que se han lanzado. Otra interpretación que nos retrotrae a los primeros autores que empezamos citando (Pérez Díaz et al. , 1996) es que hay descoordinación entre diversas ramas del ejecutivo, y especialmente entre medio ambiente y el agro, habiendo ganado la batalla el segundo al bloquear cualquier intento del primero por hacer a los regantes responsables de los costes cuyo uso del agua imputan al resto de la sociedad y por proseguir el proyecto de expansionar el regadío; o, como complemento con lo anterior, que no hay coordinación entre los objetivos conjuntos de los distintos gobiernos regionales que concurren a la lucha por los recursos hídricos.

Por fortuna, las obligaciones a las que España debe supeditar en parte su política traerán frutos, sin que nuestros políticos que las deban rendir asuman ningún coste derivado de aplicarla, al venir impuestas del exterior. Nos referimos a la Directiva Marco de la UE sobre Política de Aguas, que ayudará a nuestro país a trasladar a todos los consumidores una idea clara de que el agua es un recurso económico escaso, pero que no por ello debe faltar; y, por otro lado, los futuros acuerdos de la nueva Ronda de Singapur de la Organización Mundial del Comercio, donde las ayudas a los regantes serán un argumento que esgrimirá la UE en su batalla contra los EEUU y en virtud del cual la rentabilidad del regadío, tal y como lo concebimos ahora, será puesta en entredicho.

No debe dejarse en el tintero algo común en otros países avanzados, que escasea en el nuestro: la educación. Que el agua sea indiscutiblemente un recurso natural económico es un hecho sobre el que no todas las personas han podido tomar conciencia; y las palabras deben acompañarse de hechos, para que el ciudadano tenga estímulos positivos, y no sólo negativos en su factura de agua. Por ejemplo, los parques gastan en conjunto poca agua pero tienen un efecto educativo no despreciable; la xero-jardinería, el empleo de especies arbóreas adaptadas a cada zona, los parterres ornamentales compuestos por especies de bajo consumo, el trazado de drenajes que permitan la recuperación de las aguas no aprovechadas o el uso restringido de praderas son elementos demostrativos que deberían acompañarse de exigentes facturas de agua que expliquen cómo se depura, qué calidad del agua se devuelve a los cauces y qué retos futuros se pretenden. Lo que se pretende con la educación es un cambio de hábitos de consumo, con lo que se conseguirán ahorros de agua de poca cuantía, pero más fundamentalmente se intenta que los ciudadanos adquieran una conciencia más clara del valor cultural y económico que tiene el agua, hasta el punto de que cambien sus gustos, sus preferencias estéticas 
y su visión de lo que debe ser la gestión del agua. De este modo entenderán mejor las características de los bienes públicos, la necesidad de favorecer actividades sin efectos externos y aprenderán que muchos de los riesgos ligados al agua que actualmente nos asustan, son riesgos nacidos en parte de la conducta del hombre.

\section{Notas}

1 Trabajos en curso realizados por los investigadores Leandro del Moral, Consuelo Giansante y Luis Babiano de la Facultad de Geografia de la Universidad de Sevilla, demuestran que la Confederación Hidrográfica del Guadalquivir dio el visto a con. cesiones para riegos sociales en los años 80 sin examinar las garantías con que podrían servirse los caudales cedidos. Esta conducta explica en parte la gran vulnerabilidad a las sequías de la Cuanca del Guadalquivir. (Investigación financiada por la UE: Societal and Institutional Responses to Climate Change and Climatic Hazards: Ma. naging Flood and Drought Risks (SIRCH). Direction Générale XII, Science, Research and Development. Contract: $\mathrm{n}^{\circ}$ ENV4-CT97-0447. 1998-2000.

2 Se trata de un trabajo en curso desarrollado en el contexto del proyecto referenciado en la nota 1.

3 Cuando Cinco Días (27/8/1999) publica que "Agricultores y Andalucía exigen 250 millardos para paliar sequían es paradójico constatar que en marzo de 1999, el año más seco desde 1840, la Confederación Hidrográfica del Guadalquivir propuso repartir a sus regantes ( 300.000 hectáreas que dependen de la regulación general de la cuenca) la reserva de $12.000 \mathrm{~m} 3 / \mathrm{ha}$ que tenían almacenados asignando $4.000 \mathrm{~m} 3 / \mathrm{ha}$ a las campañas de riego de 1999,2000 y 2001. Los regantes no aceptaron la propuesta y exigieron para la campaña $1999,6.000 \mathrm{~m} 3 / \mathrm{ha}$, una dotación que aumenta notablemente la probabilidad de sequía hidrológica de las campañas 2000 y 2001. Inexplicable e irresponsablemente, la Confederación del Guadalquivir aceptó la petición y se concedió a los regantes una dotación de agua para riego absolutamente normal, en el año más seco de los últimos 150 años y con los embalses al $60 \%$ de capacidad.

\section{Bibliografía}

Blanco Fonseca, M. (1999): La economía del agua: análisis de politicas de modernización y mejora de regadios. Tesis Doctoral. Universidad Politécnica de Madrid.

Calatrava, J., Garrido, A. e Iglesias. E. (1999): Economics applied to drought planning and management for damage mitigation. Proyecto SIRCH. Working Paper \#2. Oxford.

Easter, K.W.; M.W. Rosegrant y A. Dinar (1998): Markets for Water - Potential and Performance. Kluwer Academic Publishers, Norwell, Massachusetts.

EmBiD Iruso, (1999): «El mercado del agua. Consideraciones jurídicas en torno al Proyecto de Reforma de la Ley de Aguas». Gestión Ambiental (en prensa).

GARRIDO, A. (1999) "El mercado del agua. Una visión desde la perspectova económica". Gestión Ambiental (en prensa). 


\section{La economía del agua en España}

Garrido, A. y A. Gómez Ramos (1999): "Socio-economic aspects of droughts». Presentado en el Exploratory Workshop on Drought and Drought Mitigation in Europe. Space Applications Institue, Joint Research Centre, Ispra, Italia, 1-3 marzo.

Garrido, A., Varela Ortega, C. y Sumpsi, J.M. (1997) "The interaction of agricultural pricing policies and water districts' modernization programs: a question with unexpected answerss. Comunicación a la Eighth Annual Conference of the European Assocation of Environmental and Resource Economists, 26-28 junio, Tilburg, Holanda.

Howe, C.W., D.R. Schuermeier y W.D. Shaw (1986): Innovative Approaches to Water Allocation: The Potential for Water Markets. Water Resources Research 22: 439-445.

Moreu Ballonga, J.L. (1999): "Una explicación jurídica sobre el mercado del agua". El País 1123, 31 de mayo.

PARKER; D.D. y Y. Tsur. (1998): Decentralization and Coordination of Water Resource Management. Kluwer Academic Publishers, Norwell, Massachusetts.

Pérez Dfaz, V., J. Mezo, y B. Álvarez Miranda. (1996): Politica y economía del agua en España. Circulo de Empresarios, Madrid.

Rawls, J. (1973): A Theory of Justice. Oxford University Press.

SAURI, D. y F.M. MuÑoz (1999): The limits of ecological modernization in the multiplied city: Equity and conflict over water costs in the Metropolitan Area of Barcelona. Comunicación presentada a la Conferencia "Sustainability, Risk and Nature: the Political Ecology of Water in Advanced Societies" School of Geograpghy y The Oxford Centre of Water Research, Oxford, 15.17 de abril.

Sumpsi Viñas J.M.; Garrido Colmenero, A.; Blanco Fonseca, M.; Varela Ortega C. e Iglesias Martinez, E. (1998). Economía y Políticas de gestión del agua en la agricultura. Mundi-Prensa, Madrid, $351 \mathrm{pp}$.

WATTERS, P.A. (1995): Efficient pricing of water transfer options: non-structural solutions for flexible water suppliers. Tesis doctoral, Universidad de California, Riverside. 